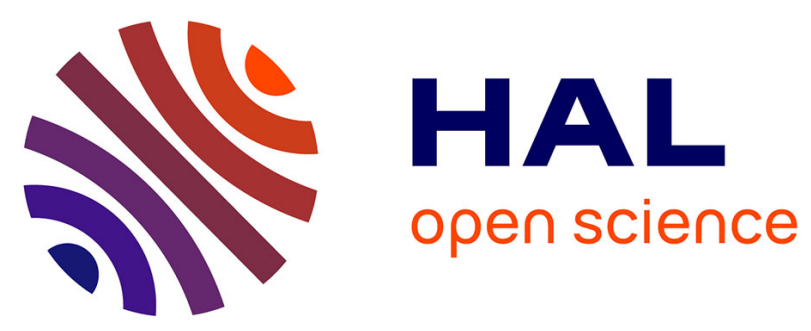

\title{
Thoracic Stent-Graft Migration: The Role of the Geometric Modifications of the Stent-Graft at 3 years
}

Bahaa Nasr, Joel Savean, Bénédicte Albert, Ali Badra, Jacques Braesco, Michel Nonent, Pierre Gouny, Dimitris Visvikis, Hadi Fayad

\section{- To cite this version:}

Bahaa Nasr, Joel Savean, Bénédicte Albert, Ali Badra, Jacques Braesco, et al.. Thoracic Stent-Graft Migration: The Role of the Geometric Modifications of the Stent-Graft at 3 years. Annals of Vascular Surgery, 2019, 58, pp.16 - 23. 10.1016/j.avsg.2018.10.024 . hal-03486107

\section{HAL Id: hal-03486107 https://hal.science/hal-03486107}

Submitted on 20 Dec 2021

HAL is a multi-disciplinary open access archive for the deposit and dissemination of scientific research documents, whether they are published or not. The documents may come from teaching and research institutions in France or abroad, or from public or private research centers.
L'archive ouverte pluridisciplinaire HAL, est destinée au dépôt et à la diffusion de documents scientifiques de niveau recherche, publiés ou non, émanant des établissements d'enseignement et de recherche français ou étrangers, des laboratoires publics ou privés.

\section{(c)(1) $\$$}

Distributed under a Creative Commons Attribution - NonCommerciall 4.0 International 
Thoracic stent-graft migration, the role of the geometric modifications of the stent-graft at 3 years.

Bahaa Nasr ${ }^{\text {a,c }}$; Joel Savean ${ }^{\text {b; }}$ Bénédicte Albert ${ }^{a}$; Ali Badra ${ }^{\text {a }}$ Jacques Braesco ${ }^{\text {a; }}$ Michel Nonent ${ }^{\mathrm{a}, \mathrm{d}}$; Pierre Gouny ${ }^{\mathrm{a}, \mathrm{c}}$; Dimitris Visvikis ${ }^{\mathrm{b}}$; Hadi Fayad ${ }^{\mathrm{e}}$.

${ }^{\text {a }}$ Service de Chirurgie Vasculaire, CHU Brest, Brest, F-29200 France

b INSERM UMR 1101, LaTIM, CHU Morvan, Brest, F-29200 France

${ }^{\mathrm{c}}$ Université de Bretagne Occidentale, Brest, F-29200 France

${ }^{\mathrm{d}}$ Service de radiologie, CHU Brest, Brest, F-29200 France

${ }^{\mathrm{e}}$ PET/CT center, OHS Hamad Medical Corporation, Doha, Qatar

\section{Corresponding author:}

Bahaa Nasr

Service de Chirurgie Vasculaire, CHU de Brest, Brest, F-29200 France

Phone: +33298347428

Fax: +33298347810

E-mail:nasr.bahaa@gmail.com 


\section{Abstract (304)}

\section{Background:}

To date, clinical and experimental studies of stent-graft migration have focused on aortic morphology and blood flow. However, thoracic endovascular aortic repair (TEVAR) is not an instant fixation of the stent-graft in the aortic lumen, but rather a continuous process of deformation and three-dimensional change in the configuration and the geometry of the stentgraft. The aim of this study was to analyse the geometric evolution of the aortic stent-graft in the proximal attachment zone at mid-term follow-up and its impact on the stent-graft (SG) migration.

\section{Methods:}

Sixty-two patients underwent TEVAR for thoracic aortic aneurysm from 2007 till 2013. Thirty patients were treated and had a complete clinical and morphological follow-up at 1 month and 3 years. We calculated the stent-graft radius of curvature (RC) change at the proximal attachment zone "P" on the postoperative CT scan at 1 month and 3 years.

\section{Results:}

There were 19 atheromatous aneurysms, 8 post-dissection aneurysms and 3 post-traumatic aneurysms. Two patients were treated at zone 1, seven at zone 2, and twenty-one at zone 3 . The median decrease of the RC at "P" was of $11 \mathrm{~mm}$ (Interquartile range IQR, $6.5 \mathrm{~mm}$; range, 1-29 mm). A greater decrease in RC was identified in patients with hostile proximal neck having: large diameter $(\mathrm{P}=0.006)$, short neck length $(\mathrm{P}=0.04)$, and neck thrombus grade II and III $(\mathrm{P}=0.02)$. In the migration group, the $\mathrm{RC}$ of "P" decreased significantly at 3 years 
(27.5 mm vs $18.25 \mathrm{~mm} ; \mathrm{P}=0.03$ ). Three patients had type I endoleak and showed a decrease of the RC at "P" (42 vs $13 \mathrm{~mm} ; 28$ vs $15 \mathrm{~mm} ; 24$ vs $9 \mathrm{~mm}$ ).

\section{Conclusions:}

The stent-graft seems to have geometric changes in the proximal attachment zone over the time. The increase of stent-graft curvature might be a predictor for stent-graft migration, and may prompt prophylactic re-intervention. 


\section{Introduction}

Stent-graft has developed as a safe and effective treatment for descending thoracic aortic aneurysms ${ }^{1-3}$. However, while early results of this technology have been encouraging, the issue of long-term durability is still of central importance to the technology's ultimate success. Stent-grafts are prone to late failure due to migration resulting from several factors; such as aortic anatomy ${ }^{4,5}$, pulsatile forces of blood flow ${ }^{6-8}$, and stent-graft geometrical configurations ${ }^{9-11}$. In-vitro and computational studies have been conducted to investigate the magnitude of displacement forces acting on the stent-graft. Figueroa et al reported that stentgraft movement is related to the magnitude and to the direction of the displacement force acting on aortic stent-graft ${ }^{12}$. Furthermore, It has been shown previously, in endovascular abdominal aortic aneurysm repair, that stent-graft displacement forces' magnitude increased with stent-graft angulation ${ }^{10,11}$. TEVAR is not an instant fixation of the stent-graft in the aortic lumen, but rather a continuous process of deformation and three-dimensional change in the configuration and the geometry of the stent-graft during a post-TEVAR aneurysm shrinkage ${ }^{13}$. The deformation of the stent-graft, especially at the proximal attachment zone, is largely unknown.

The aim of this study was to describe the aortic stent-graft curvature changes occurring in the proximal attachment zone over a period of 3 years following implantation, and to identify its impact in thoracic stent-graft migration. 


\section{Materials and Methods}

We retrospectively reviewed patients who underwent TEVAR in our institution from January 2007 to June 2013. Overall, 62 patients underwent TEVAR (Figure 1). Of these, 30 patients (23 male; median age 68.5; IQR 14, range, 61-75 years) were considered for the present study. Patients treated for aortic dissection, intramural hematomas and traumatic transection were excluded. Further, patients with incomplete follow-up images at 1 month and 3 years were also excluded. Moreover, exclusion was also applied on patients treated after June 2013 in order to have 36 months follow up. The study was approved by the institutional review board (2016.CE25), and all patients provided informed consent for the procedures.

\section{Preoperative and postoperative data}

Case notes of all patients were collected. Data relating to demographics and comorbidity were recorded. For the preoperative sizing parameters, the first author performed blinded measurements on the original images. These include proximal and distal attachment zones ${ }^{14,15}$, attachment site dimensions (thrombus and calcification grade, diameter, and length), and the length of the aneurysm. Diameter was measured perpendicular to a 3D centreline flow of the vessel ${ }^{15}$. Intraoperative adjunctive maneuvers were also collected, essentially those used for the management of endoleak.

Patient follow-up was provided by vascular surgeons. Post-procedure outcomes were determined by clinical follow-up and CT scans. Patient CT angiography was performed at 1 month, 12 months postoperatively and then annually with the same parameters as those used in the preoperative CT study. 


\section{Imaging analysis protocol}

Preoperative and postoperative CT-scans were acquired at a single institution, with a $1 \mathrm{~mm}$ slice CT scan $\left(512 \times 512 \times 270\right.$ voxels; in-plane resolution $0.78 \times 0.78 \mathrm{~mm}$; Somatom ${ }^{\circledR}$, Siemens, Munich, Germany) in all patients. Three scanners were acquired for each patient: a preoperative CT scan (T0) and two postoperative CT scans at 1 month (T1) and 36 months (T2) follow-up. The preoperative CT scan allowed, in addition to the measurements generally required before ordering the stent-graft, to calculate other parameters according to the reporting standards ${ }^{15}$. Imaging data at $\mathrm{T} 1$ and $\mathrm{T} 2$ were collected as axial images and were transferred to a workstation (Amira 6.0, Mercury computer systems, USA). A threedimensional (3D) arterial lumen centreline was automatically extracted from the ascending aorta to the aortic bifurcation and was manually adjusted as necessary. For each case, we placed a landmark "P" on the centreline corresponding to the proximal landing zone termination (Figure 2). The Cartesian coordinates of the centreline and the landmark were exported to the Rhinoceros ${ }^{\circledR}$ software (McNeel Europe, Barcelona) to calculate the radius of curvature (RC) of "P" at T1 and T2.

\section{Endpoints and definitions}

The primary endpoint was the stent-graft curvature change at 3 years follow-up, and its impact in the stent-graft migration. The stent-graft curvature change was measured by the radius of curvature change at "P". Pre-specified secondary outcomes included endoleak and stent fracture.

The radius of curvature at a particular point is defined as the radius of the approximating circle, and it indicates the level of curvature. The circle, from which the $\mathrm{RC}$ was derived, was computed automatically by the Rhinoceros ${ }^{\circledR}$ software (McNeel Europe, Barcelona). More RC is high, more the outline approximates a straight line, and vice versa. Therefore, a decrease of 
RC between T1 and T2 means an increase in the curvature. Stent fractures were classified according to the Jaff et al. Classification ${ }^{16}$. Stent-graft migration, which is the movement of the stent-graft from its initial deployment site, has been defined as movement $>10 \mathrm{~mm}$. According to TEVAR reporting standard ${ }^{15}$, the migration was measured from the centreline after checking the stability of the thoracic aortic length. In this case, the migration was calculated between the proximal native vasculature reference point (the innominate artery, the left common carotid artery or the subclavian artery according to the proximal fixation zone) and the proximal stent tip.

\section{Statistical analysis}

Continuous variables are summarized with median, interquartile range (IQR), and range. Categorical variables are summarized with frequencies and percentages and compared with a Fisher exact test. Quantitative variables were compared using the non-parametric test of Mann-Whitney U or Wilcoxon as appropriate. Correlation was calculated using Spearman's coefficient $(r)$. Statistical analysis was performed using GraphPad Prism ${ }^{\circledR}$ software version 6.0 (GraphPad Software Inc, La Jolla, CA, USA). A P value of .05 was set as a statistical significance threshold. 


\section{Results}

The demographic and aneurysm characteristics of the patients are listed in table I. There were 19 atheromatous aneurysms, 8 post-dissection aneurysms and 3 post-traumatic aneurysms. Distribution of proximal landing zones was as follow: zone $1(n=2)$, zone 2 $(n=7)$, and zone $3(n=21)$. For zone 1 , all patients had revascularization of the left common carotid artery and of the left subclavian artery (LSA). For zone 2, 4 patients had a LSA revascularization. The number of stent-grafts per case was 2 (IQR, 2; range, 1-3). A total of 49 stent grafts corresponding to different stent graft types were deployed: Zenith TX1/TX2 (Cook Inc, Bloomington, IN, USA) $(n=4, n=8)$, TAG, C-TAG (W.L Gore \& Associates, Flagstaff, AZ, USA) ( $\mathrm{n}=15, \mathrm{n}=10)$, Talent, and Valiant (Medtronic vascular, SANTA Rosa, CA, USA) $(n=4, n=8)$. The stent graft coverage median length was $220 \mathrm{~mm}$ (IQR, $169 \mathrm{~mm}$; range, $131-300 \mathrm{~mm})$.

The radius of curvature at "P" decreased in $43.3 \%$ of patients $(n=13)$ at 36 months. For those patients, the median decrease of the RC was of $11 \mathrm{~mm}$ (IQR, $6.5 \mathrm{~mm}$; range, 9- $29 \mathrm{~mm}$ ) (Figure 3). A greater decrease in RC was identified in patients with hostile proximal neck: large diameter $(>30 \mathrm{~mm})(\mathrm{P}=0.006)$, short neck length $(<20 \mathrm{~mm})(\mathrm{P}=0.04)$ and neck with thrombus grade II and III ( $\mathrm{P}=0.02)$ (table II). We described a significant negative correlation between the proximal neck diameter and the evolution of the proximal graft segment curvature $(\mathrm{r}=-0.59, \mathrm{P}=0.001)$ (Figure $4 \mathrm{~A})$. There was also a significant positive correlation between the proximal neck length and the evolution of the proximal graft segment curvature $(\mathrm{r}=0.52, \mathrm{P}=0.003)($ Figure 4B).

Caudal migration of the stent-graft was observed in 7 patients (23\%). Among them, 3 patients required re-intervention to treat the type I endoleak. There was no statistically significant difference at baseline between the migration group and the entire group (IQR, 19.75; range, 
20-48 mm vs IQR, 14.25; range, 13-69mm; $\mathrm{p}=0.84$ ). The $\mathrm{RC}$ of "P" in the migration group decreased significantly at 36 months $(27.5 \mathrm{~mm}$; IQR, 19.75; range, 20-48 mm vs. $18 \mathrm{~mm}$; IQR, 18.25; range, 9-34 mm; $\mathrm{P}=0.03$ ). A statistically significant difference was also found between the migration group and non-migration group concerning $\mathrm{RC}$ decrease. This decrease was more important in the migration group $(-9.5 \mathrm{~mm}$; IQR, $12.5 \mathrm{~mm}$; range, -27 to $-5 \mathrm{~mm}$ vs $1.5 \mathrm{~mm}$; IQR, $13.5 \mathrm{~mm}$; range, -29 to $20 \mathrm{~mm}$; $\mathrm{p}=0.02$ ).

Overall, 3 patients were diagnosed with a type I endoleak, 3 with a type II endoleak and 1 patient with a type III endoleak. The 3 patients with type I endoleak showed a decrease of the RC of the proximal stent-graft segment (42 vs. $13 \mathrm{~mm} ; 28 \mathrm{vs} .15 \mathrm{~mm}$; and 24 vs. $9 \mathrm{~mm}$ ). We reported only one stent fracture, without clinical consequence, that was observed at 24 months. The stent fracture was classified as a type 1 fracture and occurred at proximal stent graft level in a patient treated in proximal landing zone 3, with a RC decrease of $29 \mathrm{~mm}$ (42 vs. $13 \mathrm{~mm})$. 


\section{Discussion}

Previous clinical and experimental studies of TEVAR outcomes have focused on the aortic morphological characteristics, such as aortic neck diameter, length, angulation, and aortic tortuosity ${ }^{4,17-19}$. However, stent graft can move laterally within the aneurysm sac, thus affecting the position of the endograft regarding attachment zones ${ }^{12,20}$.

To our Knowledge, this study is the first thoracic stent graft attachment zone geometrical change analysis. The main finding was the curvature increase of the stentgraft in the proximal attachment zone, and its association with stent-graft migration. Our results are consistent with Figueroa findings 12,21. He showed that stent-graft displacement force may change if the geometry of the stent-graft changes significantly as a result of stent-graft movement ${ }^{12}$. He also showed that the curvature increase is associated with an increase of displacement force migration. A $50 \%$ decrease of the curvature causes a displacement force decrease of $0.8 \mathrm{~N}^{21}$.

The predictive factors of proximal stent-graft curvature increase were: proximal neck diameter $>30 \mathrm{~mm}$, proximal neck length $<20 \mathrm{~mm}$, and proximal neck with grade II and III thrombus. In short neck, the stent-graft is in full contact with the aortic wall on the lesser curve of the distal arch, unlike the greater curve. Yet, the stent-graft proximal fixation is not circumferential, and the risk of proximal stent-graft curvature is greater 13. Prassad has also shown that stent-graft positional stability is affected by the frictional interaction between the aorta and the stent-graft, which can be significantly altered by the presence of thrombus ${ }^{13}$. Endoleaks can also be a predictor factor of proximal stentgraft curvature increase. Endoleaks increased pressure in the aneurysmal sac 22 promote lateral movements of the stent-graft in the aneurysmal sac ${ }^{12}$. The stent-graft is fixed to the aorta by an oversizing, which reduces its compliance at this level. There is 
therefore changing in the forces acting in the stent-graft, which may cause deformation of the stent by increasing the curvature of the proximal stent-graft segment. In endovascular treatment of the abdominal aortic aneurysm, Schuurmann showed that a curvature over infrarenal aortic neck may cause stent graft tilt and may induce lateral forces on it ${ }^{23}$. Our results are consistent since we demonstrated an increase in the curvature of the proximal stent-graft attachment, especially when the curvature was significant at $\mathrm{T} 0$.

The stent-graft migration is a redoubtable complication with TEVAR technique. It exposes to the risk of type I endoleak and aneurysm rupture ${ }^{24,25}$ and was significantly correlated to the proximal stent-graft curvature increase.

One explanation to this correlation is that the proximal stent-graft curvature increase was mostly described in hostile neck, which can increase the risk of migration. Jim reported a higher migration rate at 5 years after EVAR with large neck ( $>28 \mathrm{~mm}$ ) versus small neck $(<28 \mathrm{~mm})^{26}$. In a study of 238 patients, Stanley described a migration rate of $4.2 \%$, and identified proximal neck diameter $>28 \mathrm{~mm}$ as the only risk factor of migration ${ }^{27}$. Another possible explanation for the correlation between stent-graft migration and proximal stent-graft curvature increase is that the modification of the curvature of the proximal stentgraft segment can modify the displacement forces applied on the stent-graft. Liffman and Roos reported an increase of displacement forces associated with an increase of the curvature in asymmetric stent-graft ${ }^{10,28}$.

It seems important to monitor the proximal stent-graft curvature because it can be a predictive factor of stent-graft migration. Patients showing an increase in the proximal stent-graft curvature can be treated preventively, to avoid complication like migration or type I endoleak. An aortic cuff stent graft or the Heli-Fx EndoAnchor System (Aptus ${ }^{\circledR}$ Endosystems, Sunnyvale, Calif) can be used to improve fixation and sealing of the stent graft proximal 
segment within the proximal aortic neck ${ }^{29}$. This technique of curvature measuring can be integrated into different sizing software to assist clinicians in monitoring the evolution of this curvature.

Schuurmann demonstrated that aortic curvature is a predictor factor for late type Ia endoleak and endograft migration after EVAR ${ }^{30}$. Callaghan showed that Aortic diameter, ascending aortic angle, shape, and curvature increased across age ${ }^{31}$. As a result, we are planning to continue the monitoring of our patients in the long term, which will allow us to study the modification of the aortic and stent-graft curvature with age.

Schuurmann described that curvature calculation is the most accurate method of representing aortic curvature ${ }^{23}$. He reported advantages to calculate curvature instead angulation: First, measurements and calculations are performed entirely on the centreline. Secondly, curvature can be calculated over all centreline coordinates. This enables software manufacturers to include calculations of maximum and average curvature over specific aortic or stent-graft segments. Finally, distance of the largest curvature from baseline can be measured over the centreline enabling comparison of the largest curvature location between multiple follow-up CT scans. This is useful for proper quantification of eventual displacement of the largest curvature over time and changes in the proximal part of the stent-graft over time.

The present study is limited by its retrospective and monocentric design as well as the diversity of stent-graft used. We were interested by aneurysmal pathology, but etiology of the aneurysm remained heterogeneous. Pathology evolution and aortic remodelling are different between the three etiologies. Furthermore, the small size of the population does not allow powerful statistical analysis. This preliminary study needs to be confirmed with a larger population.

Finally, using RC had two limits: first, $\mathrm{RC}$ is calculated in each point of the central line i.e. precision of the RC depends on the correctness of the central line. Second, the use of the RC 
has not been yet established and validated clinically. As a result, integrating this measurement system into sizing softwares' is a prerequisite.

\section{Conclusions}

The stent-graft seems to have geometrical changes in the proximal attachment zone, marked by an increase of the curvature. This curvature increase might be a predictor of stent-graft migration. These findings suggest that stent-graft geometrical changes can be included in the monitoring of the thoracic stent-graft to propose preventive treatment in order to avoid complication like migration or type I endoleak. 


\section{Notes:}

This study was presented at the $33^{\text {rd }}$ congress of the French society of vascular and endovascular surgery (SCVE), Nice, France, Jun 29- July 2, 2018.

\section{Funding}

This research did not receive any specific grant from funding agencies in the public, commercial, or not-for-profit sectors. 


\section{References}

1. Bell RE, Taylor PR, Aukett M, et al. Mid-term results for second-generation thoracic stent grafts. Br J Surg 2003; 90: 811-7.

2. Makaroun MS, Dillavou ED, Wheatley GH, et al. Five-year results of endovascular treatment with the Gore TAG device compared with open repair of thoracic aortic aneurysms. J Vasc Surg 2008; 47:912-8.

3. Matsumura JS, Cambria RP, Dake MD, et al. International controlled clinical trial of thoracic endovascular aneurysm repair with the Zenith TX2 endovascular graft: 1-year results. J Vasc Surg 2008; 47:247-257; discussion 257.

4. Boufi M, Guivier-Curien C, Dona B, et al. Risk Factor Analysis for the Mal-Positioning of Thoracic Aortic Stent Grafts. Eur J Vasc Endovasc Surg 2016; 52:56-63.

5. Bowman JN, Silverberg D, Ellozy S, et al. The role of anatomic factors in predicting success of endovascular repair of thoracic aortic aneurysms. Vasc Endovascular Surg $2010 ; 44: 101-4$.

6. Prasad A, To LK, Gorrepati ML, et al. Computational analysis of stresses acting on intermodular junctions in thoracic aortic endografts. J Endovasc Ther $2011 ; 18: 559-68$.

7. Muhs BE, Vincken KL, van Prehn J, et al. Dynamic cine-CT angiography for the evaluation of the thoracic aorta; insight in dynamic changes with implications for thoracic endograft treatment. Eur J Vasc Endovasc Surg 2006 ;32:532-6.

8. van Prehn J, Bartels LW, Mestres G, et al. Dynamic aortic changes in patients with thoracic aortic aneurysms evaluated with electrocardiography-triggered computed 
tomographic angiography before and after thoracic endovascular aneurysm repair: preliminary results. Ann Vasc Surg 2009; 23:291-7.

9. Langs G, Paragios N, Desgranges $\mathrm{P}$, et al. Learning deformation and structure simultaneously: in situ endograft deformation analysis. Med Image Anal $2011 ; 15: 12$ 21.

10. Roos H, Tokarev M, Chernoray V, et al. Displacement Forces in Stent Grafts: Influence of Diameter Variation and Curvature Asymmetry. Eur J Vasc Endovasc Surg 2016; $52: 150-6$.

11. Roos H, Ghaffari M, Falkenberg M, et al. Displacement forces in iliac landing zones and stent graft interconnections in endovascular aortic repair: an experimental study. Eur $\mathbf{J}$ Vasc Endovasc Surg 2014; 47:262-7.

12. Figueroa CA, Taylor CA, Yeh V, et al. Preliminary 3D computational analysis of the relationship between aortic displacement force and direction of endograft movement. $\mathbf{J}$ Vasc Surg 2010; 51:1488-1497; discussion 1497.

13. Prasad A, Xiao N, Gong X-Y, et al. A computational framework for investigating the positional stability of aortic endografts. Biomech Model Mechanobiol. 2013; 12:869-87.

14. Ishimaru S. Endografting of the aortic arch. J Endovasc Ther 2004; 11 Suppl 2:II62-71.

15. Fillinger MF, Greenberg RK, Society for Vascular Surgery Ad Hoc Committee on TEVAR Reporting Standards. Reporting standards for thoracic endovascular aortic repair (TEVAR). J Vasc Surg 2010; 52:1022-1033, 1033.

16. Jaff M, Dake M, Pompa J, et al. Standardized evaluation and reporting of stent fractures in clinical trials of noncoronary devices. Catheter Cardiovasc Interv 2007; 70:460-2. 
17. Piffaretti G, Mariscalco G, Lomazzi C, et al. Predictive factors for endoleaks after thoracic aortic aneurysm endograft repair. J Thorac Cardiovasc Surg 2009; 138:880-5.

18. Ueda T, Takaoka H, Raman B, et al. Impact of quantitatively determined native thoracic aortic tortuosity on endoleak development after thoracic endovascular aortic repair. AJR Am J Roentgenol $2011 ; 197: W 1140-1146$.

19. Chen C-K, Liang I-P, Chang H-T, et al. Impact on outcomes by measuring tortuosity with reporting standards for thoracic endovascular aortic repair. J Vasc Surg 2014; 60:937-44.

20. Rafii BY, Abilez OJ, Benharash P, et al. Lateral movement of endografts within the aneurysm sac is an indicator of stent-graft instability. J Endovasc Ther 2008; 15:335-43.

21. Figueroa CA, Taylor CA, Chiou AJ, et al. Magnitude and direction of pulsatile displacement forces acting on thoracic aortic endografts. J Endovasc Ther 2009; 16:350 8.

22. Molony DS, Callanan A, Kavanagh EG, et al. Fluid-structure interaction of a patientspecific abdominal aortic aneurysm treated with an endovascular stent-graft. Biomed Eng Online 2009 6; 8:24.

23. Schuurmann RCL, Kuster L, Slump CH, et al. Aortic Curvature Instead of Angulation Allows Improved Estimation of the True Aorto-iliac Trajectory. Eur J Vasc Endovasc Surg 2016; 51:216-24.

24. Heijmen RH, Deblier IG, Moll FL, et al. Endovascular stent-grafting for descending thoracic aortic aneurysms. Eur J Cardio-Thorac Surg 2002; 21:5-9. 
25. Makaroun MS, Dillavou ED, Kee ST, et al. Endovascular treatment of thoracic aortic aneurysms: results of the phase II multicenter trial of the GORE TAG thoracic endoprosthesis. J Vasc Surg 2005; 41:1-9.

26. Jim J, Rubin BG, Geraghty PJ, et al. A 5-year comparison of EVAR for large and small aortic necks. J Endovasc Ther 2010; 17:575-84.

27. Stanley BM, Semmens JB, Mai Q, et al. Evaluation of patient selection guidelines for endoluminal AAA repair with the Zenith Stent-Graft: the Australasian experience. J Endovasc Ther 2001; 8:457-64.

28. Liffman K, Lawrence-Brown MM, Semmens JB, et al. Analytical modeling and numerical simulation of forces in an endoluminal graft. J Endovasc Ther 2001; 8:35871.

29. Jordan WD, Mehta M, Varnagy D, et al. Results of the ANCHOR prospective, multicenter registry of EndoAnchors for type Ia endoleaks and endograft migration in patients with challenging anatomy. J Vasc Surg 2014; 60:885-892.

30. Schuurmann RCL, van Noort K, Overeem SP, Ouriel K, Jordan WD Jr, Muhs BE, 't Mannetje Y, Reijnen M, Fioole B, Ünlü Ç, Brummel P, de Vries JPM. Aortic Curvature Is a Predictor of Late Type Ia Endoleak and Migration After Endovascular Aneurysm Repair. J Endovasc Ther. 2017; 24(3): 411-417.

31. Callaghan FM, Bannon P, Barin E, Celemajer D, Jeremy R, Figtree G, Grieve SM. Agerelated changes of shape and flow dynamics in healthy adult aortas: A 4D flow MRI study. J Magn Reson imaging. 2018, doi: 10.1002/jmri.26210. 


\section{Titles of tables and figures:}

Figure 1: Study flow chart showing the distribution of patients treated with thoracic stent-graft during the period of inclusion. TEVAR: thoracic endovascular aneurysm repair.

Figure 2: Schematic representation of the centreline and the landmark "p" corresponding to the proximal landing zone termination. CL: centerline.

Figure 3: A: Radius of curvature of "P" at 1-month follow-up. B: Radius of curvature of "P" at 3 years follow-up. CL: centerline, P: landmark at the proximal landing zone termination, RC: radius of curvature.

Figure 4: A: correlation between the proximal landing zone diameter and variation of the proximal stent-graft attachment curvature. B: correlation between the proximal landing zone length and variation of the proximal stent-graft attachment curvature. P: landmark at the proximal landing zone termination, RC: radius of curvature, T1: 1-month follow-up, T2: 3 years follow-up.

Table I: Clinical and anatomical characteristics

Table II: Predictive factors of the stent graft proximal attachment zone curvature evolution 


\section{2 patients treated with TEVAR}

21 patients excluded

7 deaths

6 lost to follow-up

8 absence of CT-scanner at 1 month or 36 months

\section{1 patients eligible for the study}

11 patients were excluded 4 aortic isthmus rupture 8 complicated acute type $\mathrm{B}$ dissection 


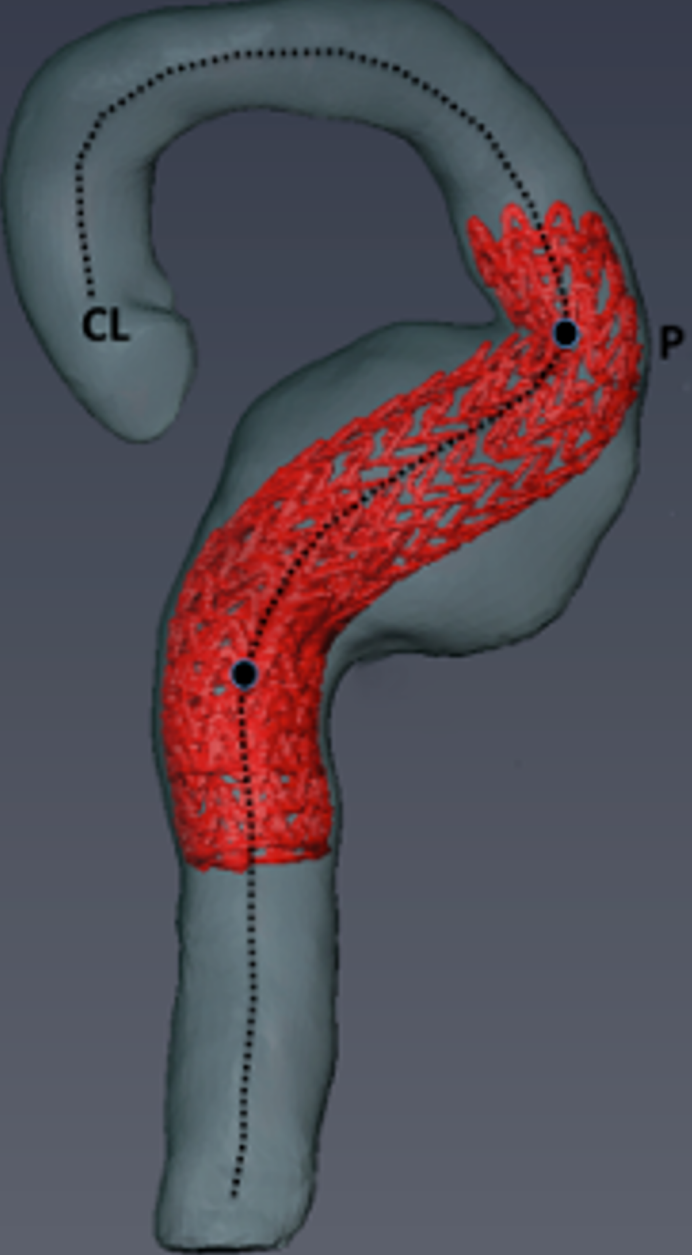



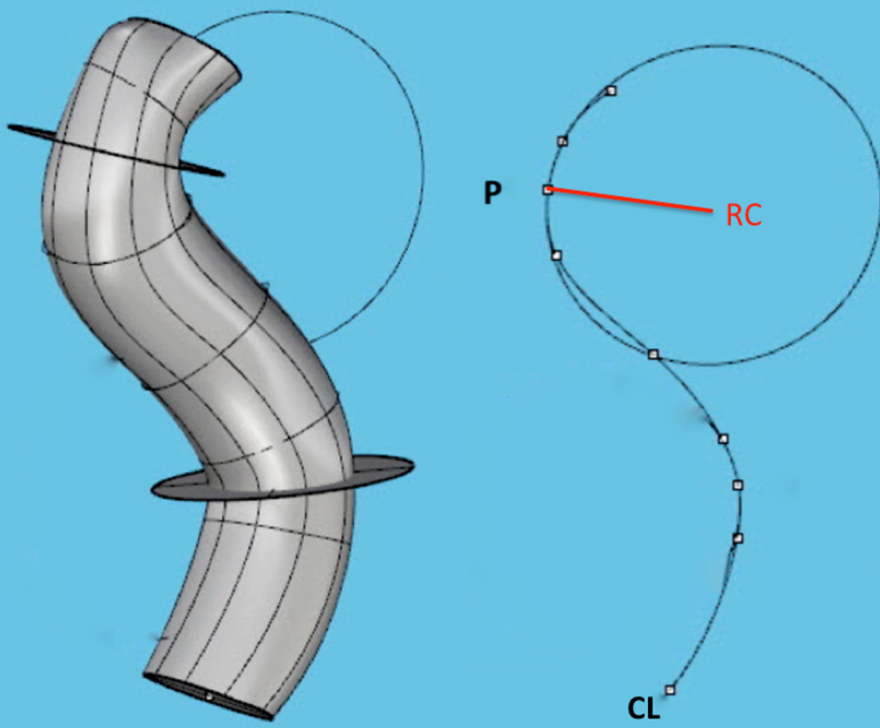

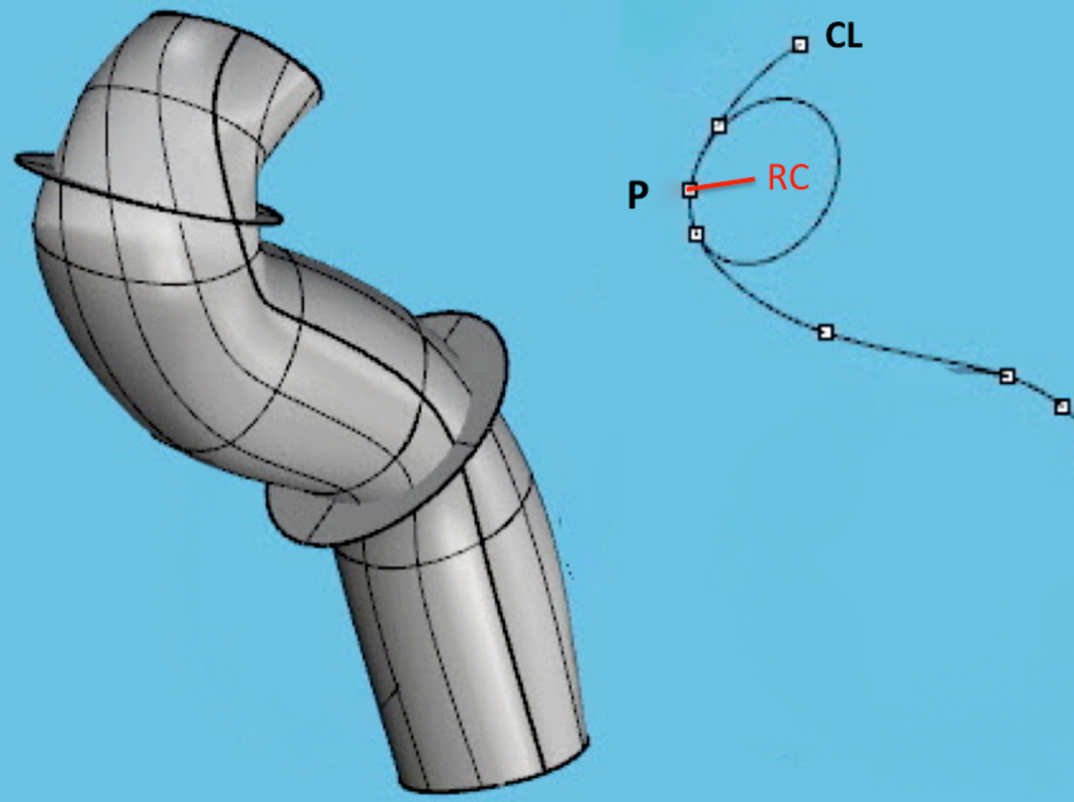


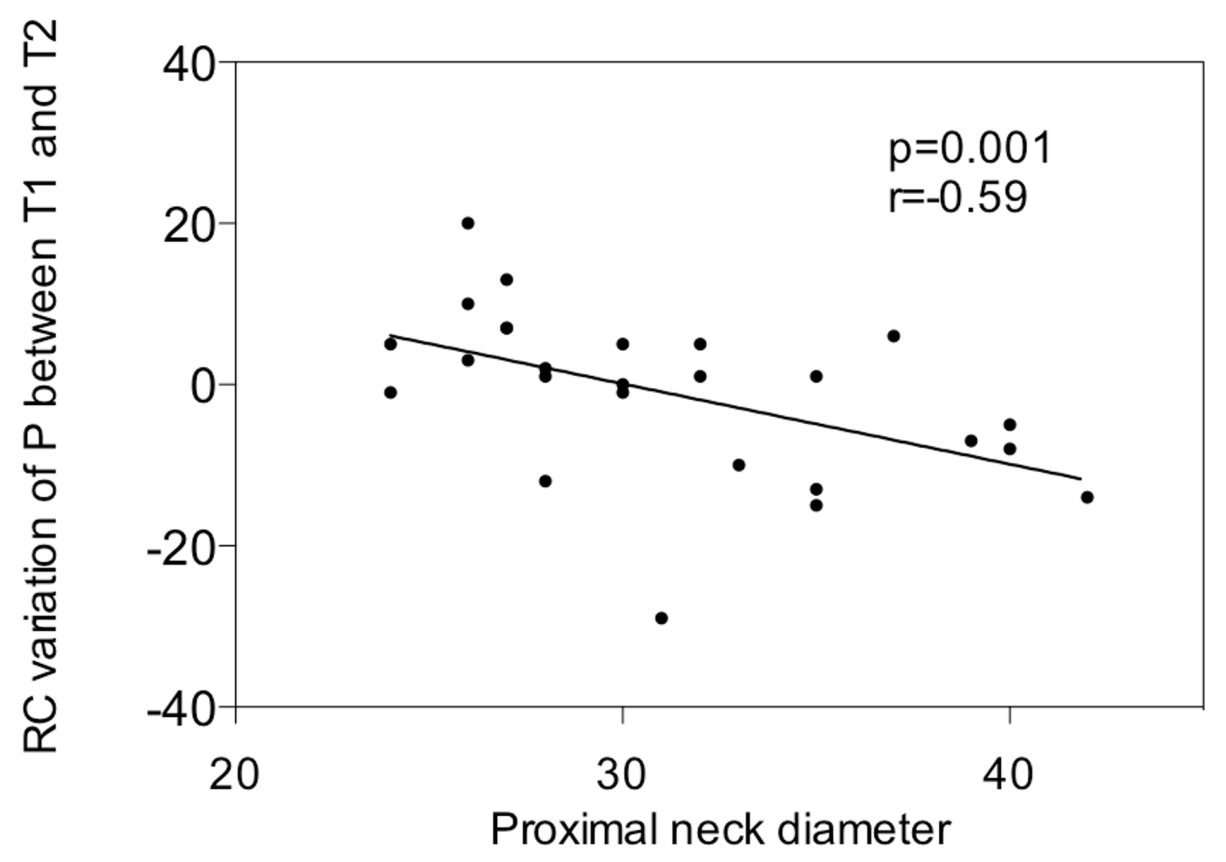




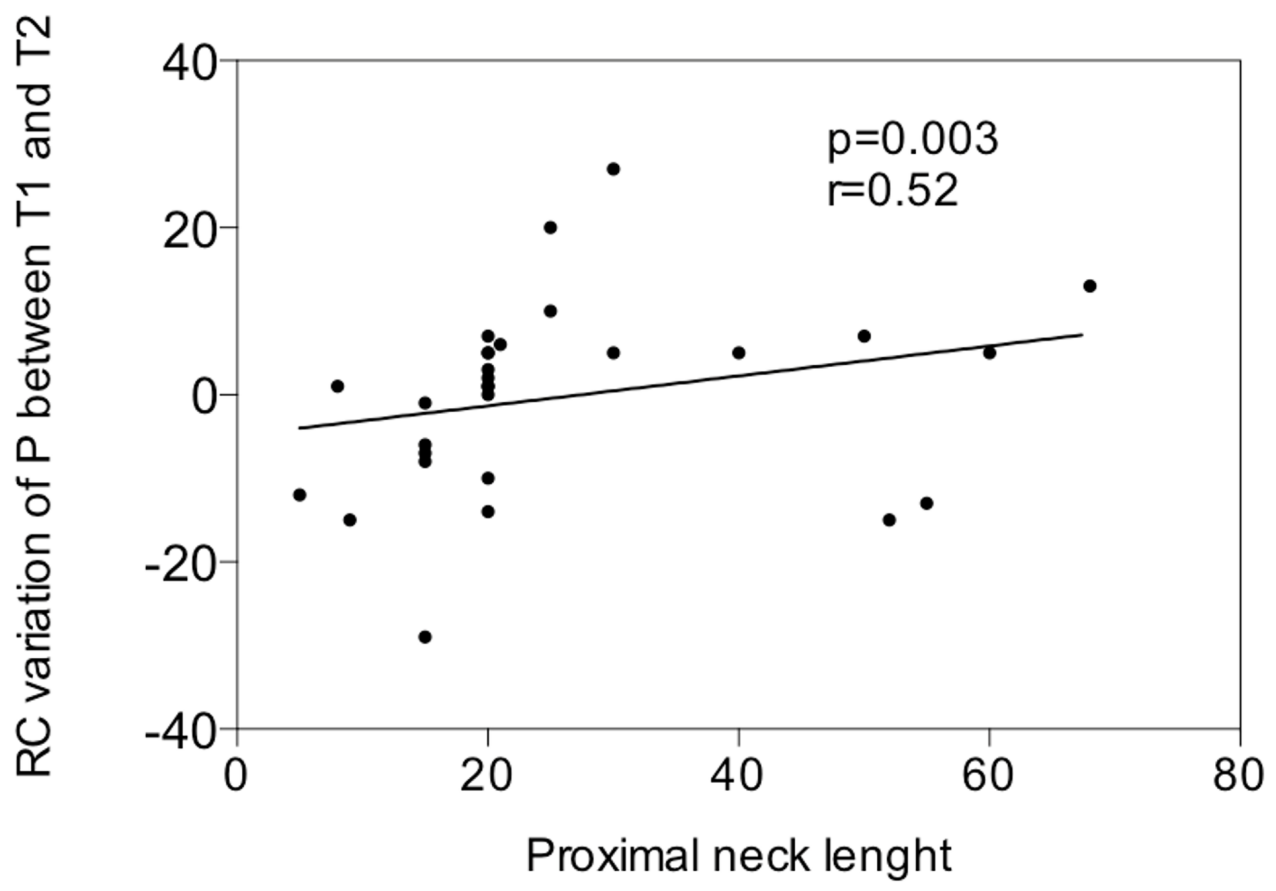


Table I. Clinical and anatomical characteristics

\begin{tabular}{ll}
\hline Characteristics & $\mathrm{n}=30$
\end{tabular}

Clinical characteristics

Age, years

$68.50(61 ; 75)$

Male, no (\%)

$23(76.60)$

ASA score ${ }^{*}$

ASA 2

$7(23.33)$

ASA 3

$21(70)$

ASA 4

$2(6.66)$

Dyslipidemia, no (\%)

$7(23.30)$

Hypertension, no (\%)

$22(66.60)$

Diabetes mellitus, no (\%)

$2(6.66)$

Coronary artery disease, no (\%)

$10(33.30)$

Chronic obstructive pulmonary disease, no (\%)

$9(30)$

Chronic renal failure, no (\%)

$5(16.66)$

Aneurysm characteristics

Maximal aneurysm diameter, $(\mathrm{mm})$

$58(55 ; 71)$

Aneurysm length, (mm)

$120(59 ; 178)$

Landing zone, no (\%)

Zone 1

$2(6.66)$

Zone 2

$7(23.33)$

Zone 3

$21(70)$

Proximal landing zone atheroma degree, no (\%)

Grade 0

$16(55)$ 


\begin{tabular}{lc}
\hline Grade I & $7(22)$ \\
Grade II & $4(14)$ \\
Grade III & $3(9)$ \\
Proximal landing zone diameter, $(\mathrm{mm})$ & $30(27 ; 33)$ \\
Proximal landing zone length, $(\mathrm{mm})$ & $20.50(15 ; 50)$ \\
Distal landing zone diameter, $(\mathrm{mm})$ & $28(25 ; 31)$ \\
Distal landing zone length, $(\mathrm{mm})$ & $43.5(32 ; 102)$ \\
& \\
\hline * ASA score: American Society of Anesthesiologists score & \\
Continuous variables are expressed as median values with $25^{\text {th }}$ and $75^{\text {th }}$ percentiles \\
Categorical variables are expressed as number $(\%)$
\end{tabular}


Table II. Predictive factors of the stent graft proximal attachment zone curvature evolution

\begin{tabular}{ccc}
\hline Variables & Radius of curvature $(\mathrm{RC})^{*}$ & $\mathrm{P}$ \\
& $\operatorname{Median}(\mathrm{Q} 1 ; \mathrm{Q} 3) \dagger$
\end{tabular}

Proximal landing zone 0.62

Zone 1

$3(1 ; 5)$

Zone 2

$-4(-10.75 ; 2.25)$

Zone 3

$4(-8.25 ; 7.75)$

Proximal landing zone diameter

0.006

$\leq 30 \mathrm{~mm}$

$5(0.25 ; 9.25)$

$>30 \mathrm{~mm}$

$-7.50(-13.75 ; 4)$

Proximal landing zone length

0.04

$<20 \mathrm{~mm}$

$-6.50(-9 ;-0.50)$

$\geq 20 \mathrm{~mm}$

$5(-2.50 ; 7)$

Proximal landing zone atheroma degree

0.02

Grade 0/I

$4(-0.50 ; 6.75)$

Grade II/III

$-10(-14.75 ; 3.75)$

Stent-graft fixation type

0.76

FreeFlo

$0.5(-11.25 ; 15.25)$

Closed web

$2.5(-7.75 ; 5.75)$

Stent-graft per case

0.82

1

$1(-9 ; 6.50)$

2

$3.50(-5.25 ; 5)$

3

$-6(-15 ; 10)$

Oversizing

0.90

$10 \%$

$4(-2.50 ; 5.50)$ 
$15 \%$

$20 \%$

Endoleak

Yes

Non
$5(2 ; 7)$

$5(-13 ; 7)$

0.02

$-9.50(-14.75 ; 2.25)$

$4(0.25 ; 6.75)$

${ }^{*} \mathrm{RC}$ : radius of curvature of the stent graft at the proximal attachment zone

†Q1: $25^{\text {th }}$ percentile, Q3: $75^{\text {th }}$ percentile 